\title{
Clinical Features and Prognosis of Nontuberculous Mycobacterial Pleuritis
}

\author{
Takahiro Ando ${ }^{a}$ Masahiro Kawashima ${ }^{a}$ Hirotoshi Matsui ${ }^{a}$ Keita Takeda ${ }^{a}$ \\ Ryota Sato $^{a}$ Nobuharu Ohshima ${ }^{a}$ Hideaki Nagai $^{a}$ Masashi Kitani ${ }^{b}$ \\ Akira Hebisawa $^{\mathrm{b}}$ Ken Ohta ${ }^{\mathrm{a}}$ \\ ${ }^{a}$ Center for Respiratory Diseases, National Hospital Organization Tokyo National Hospital, Tokyo, Japan; \\ ${ }^{\mathrm{b}}$ Department of Pathology, National Hospital Organization Tokyo National Hospital, Tokyo, Japan
}

\section{Keywords}

Nontuberculous mycobacteriosis · Pleuritis · Pneumothorax ·

Bronchopleural fistula $\cdot$ Drainage

\section{Abstract}

Background: While nontuberculous mycobacterial (NTM) pleuritis rarely complicates pulmonary NTM infection, high mortality has been reported in case reports and small studies. Objectives: The purpose of this study was to clarify the clinical features and treatment outcomes of pulmonary NTM infection cases accompanied by NTM pleuritis. Methods: Medical records of 1,044 patients with pulmonary NTM disease were retrospectively reviewed to select patients complicated by NTM-proven pleuritis. We investigated clinical characteristics, pathogens, pleural effusion examinations, radiographic findings, treatments, and clinical course of the NTM pleuritis patients. Results: Among 1,044 cases with pulmonary NTM, NTM pleuritis occurred in 15 cases (1.4\%). The mean age was 69 years with a performance status of mostly 2 or better $(80.0 \%)$, and 6 cases $(40.0 \%)$ were complicated by pneumothorax. Subpleural cavities were radiologically detected in 11 cases (73.3\%), and extrapulmonary air-fluid level was detected in 14 cases (93.3\%). Eleven patients were treated with combinations of 2-4 antimycobacterial drugs, including clarithromycin, and 2 patients were treated with isoniazid, rifampicin, and ethambutol. Chest tube drainage was performed in 11 cases, and surgical approach was added in 6 cases. The pleural effusion of 2 patients treated with only antimycobacterial medications gradually deteriorated. Two patients died from NTM pleuritis, and 1 patient died from pneumonitis during a mean of 1.8 years of follow-up. Conclusions: Comorbid NTM pleuritis was difficult to treat by medical therapy alone and resulted in a poor prognosis. In addition to antimycobacterial agents, chest tube drainage and surgical procedures in the early stages should be considered to treat NTM pleuritis. @ 2018 The Author(s)

Published by S. Karger AG, Basel

\section{Introduction}

Nontuberculous mycobacterium (NTM) is ubiquitous in the environment, frequently isolated from water and soil $[1,2]$. Thus, most NTM organisms detected from human samples have been considered as colonization or contamination. However, NTM can cause diseases, such as lung infections, lymphadenopathy, skin and soft tissue

\begin{tabular}{|c|c|}
\hline KARGER & $\begin{array}{l}\text { (C) } 2018 \text { The Author(s) } \\
\text { Published by S. Karger AG, Basel }\end{array}$ \\
\hline $\begin{array}{l}\text { E-Mail karger@karger.com } \\
\text { www.karger.com/res }\end{array}$ & $\begin{array}{l}\text { This article is licensed under the Creative Commons Attribution- } \\
\text { NonCommercial-NoDerivatives } 4.0 \text { International License (CC BY- } \\
\text { NC-ND) (http://www.karger.com/Services/OpenAccessLicense). } \\
\text { Usage and distribution for commercial purposes as well as any dis- } \\
\text { tribution of modified material requires written permission. }\end{array}$ \\
\hline
\end{tabular}

Takahiro Ando

Center for Respiratory Diseases

National Hospital Organization Tokyo National Hospital

3-1-1, Takeoka, Kiyose, Tokyo 204-8655 (Japan)

E-Mail takaando@me.com 
infections, and disseminated disease, in immunocompromised patients [3-5]. Since the guidelines on pulmonary NTM were pronounced by the American Thoracic Society (ATS)/Infectious Diseases Society of America (IDSA) [6], the prevalence of NTM infection has been reported worldwide [7-11]. The estimated incidence rate in Japan has increased from 1.5 per 100,000 in 1985 to 14.7 per 100,000 in 2014 [12]. The 3 most common pulmonary pathogen groups are Mycobacterium avium complex (MAC), M. kansasii, and M. abscessus complex in Japan [13].

While bronchopulmonary infection is one of the most common pathologies with NTM, NTM infection of the pleural space is rare in contrast to tuberculosis. Some studies reported cases of disseminated M. avium complex complicated by NTM pleuritis in immunocompromised patients $[14,15]$, and other cases of NTM pleuritis were reported in immunocompetent cases [16-22]. In the previous studies, the frequency of pleural effusion in patients with NTM infection was reported to be 3.4-6\% $[23,24]$, although those reports did not state whether mycobacterial organisms were isolated from the pleural effusion.

Only a few studies in the literature have reported on the pathogenesis, clinical course, or prognosis of NTM pleuritis, concluding that the mortality was as high as $37-$ $66 \%$ at 1 year $[25,26]$. The aim of this study was to clarify the clinical characteristics and prognosis of NTM pleuritis complicating pulmonary NTM disease.

\section{Materials and Methods}

\section{Patient Population}

We retrospectively reviewed the medical records of $1,044 \mathrm{pa}-$ tients at our institution with pulmonary NTM disease meeting the 2007 ATS/IDSA criteria between January 2007 and December 2016 [6]. The study population with NTM pleuritis was selected with the additional criteria (1) positive culture of NTM from pleural effusion or pleural biopsy or (2) positive smear of pleural effusion or pleural biopsy and positive result of nucleic acid amplification test for M. avium complex. All laboratory data and images in this report were obtained as part of routine tests in the process of diagnosis and treatment.

\section{Laboratory Test of Pleural Effusion}

The aspirated pleural effusion sample was divided into 3 parts which were used for laboratory testing and microbiological and histological studies. Microbiological studies included acidfast bacillus smear by Ziehl-Neelsen staining or fluorescent staining method and culture using the BACTEC MGIT 960 system (MGIT) or the Ogawa media, with the remaining sample being processed for transcription-reverse transcription concerted reaction [27].
Imaging Studies and Evaluation of Chest Computed

Tomography Findings

We performed chest radiography and computed tomography in all patients on admission to evaluate NTM pleuritis. The imaging studies were reviewed by 1 general diagnostic radiologist and at least 2 pulmonologists who had 5-30 years of experience in thoracic imaging to evaluate the following points: the affected area, the pattern of abnormalities (i.e., nodular bronchiectasis or fibrocavitary pattern), presence or absence of subpleural cavities, extrapulmonary air-fluid level, pneumothorax, and pleural effusion. We evaluated the amount of pleural effusion with chest radiography or computed tomography taken at the onset of the disease. The amount of pleural effusion was estimated as small (less than onethird of 1 hemithorax with chest radiography), moderate (between one-third and two-thirds of 1 hemithorax), or large (more than two-thirds of 1 hemithorax) [28].

\section{Evaluation of Clinical Features and Prognosis}

We retrospectively investigated clinical characteristics, pathogens, pleural effusion examinations, radiographic findings, treatments, clinical course, and prognoses of the 15 cases with NTMproven pleuritis. We used the Zubrod performance status to estimate patients' functional capacities [29]. Patients were followed up for at least 2 years after diagnosis or until death or loss to follow-up.

\section{Statement of Ethics}

This study was approved by the Institutional Review Board of National Hospital Organization Tokyo National Hospital (approval date: July 22, 2013; approval number: 140036). Because of the retrospective nature of the study, informed consent was not obtained from study participants. Waiver of consent to use the patient records was granted by the Institutional Review Board, and analysis of this study was carried out after anonymization of the patients' data.

\section{Results}

\section{Characteristics of NTM Pleuritis}

Between January 2007 and December 2016, in 1,044 cases with pulmonary NTM, pleuritis with NTM occurred in 15 cases (1.4\%). Their mean age was 69 years, ranging from 46 to 85 years, and 9 patients (60\%) were male (Table 1). While body mass index was lower than 18.5 in 11 cases (73\%), performance status was 2 or better in 12 cases $(80 \%)$. NTM pleuritis occurred with pneumothorax in 6 cases (40\%). Two patients had diabetes mellitus, while the other patients were immunocompetent.

Pathogens isolated from the pleural effusion were identified as M. avium in 60\% (9/15), followed by M. kansasii in 13\% (2/15) (Table 2). NTM and bacteria were isolated at the same time in 2 cases (13\%), and these patients were diagnosed as coinfection with other bacteria. Differential cell counts in pleural effusion were available in 12 cases, exhibiting neutrophil predominance in 9 cases 
Table 1. Clinical characteristics of patients with NTM pleuritis $(n=15)$

\begin{tabular}{lc}
\hline Age, years & $69.2 \pm 10.6$ \\
Male gender & $9(60)$ \\
BMI $\leq 18.5$ & $11(73)$ \\
Performance status $\geq 2$ & $12(80)$ \\
Smoking history & $9(60)$ \\
Respiratory failure & $3(20)$ \\
\hline Complications & \\
$\quad$ Pneumothorax & $6(40)$ \\
$\quad$ Diabetes mellitus & $3(20)$ \\
$\quad$ Past history of tuberculosis & $5(33)$ \\
\hline Laboratory data & \\
$\quad$ WBC count, $\mu \mathrm{L}$ & $8,260 \pm 1,425$ \\
$\quad$ Albumin, g/dL & $3.0 \pm 0.7$ \\
CRP, mg/dL & $8.9 \pm 5.8$ \\
\hline
\end{tabular}

Figures are means \pm standard deviations or $n(\%)$. NTM, nontuberculous mycobacterium; BMI, body mass index; WBC, white blood cell; CRP, C-reactive protein.

(75\%), including 2 cases of coexisting bacterial empyema. Adenosine deaminase (ADA) activity in the pleural effusion was available in 10 patients, and the mean ADA level was $152.7 \mathrm{U} / \mathrm{L}$, ranging from 43.4 to $303 \mathrm{U} / \mathrm{L}$.

\section{Radiological Findings}

Chest X-ray revealed that the area of the affected lung exceeded $50 \%$ of the total lung field in 11 cases $(73 \%)$ (Table 3). Chest computed tomography predominantly showed nodular bronchiectasis in 5 patients and fibrocavitary features in 10 patients. Subpleural cavities were detected in 11 cases (73\%). Air-fluid level was detected in the pleural spaces in 14 cases (93\%), which made us suspect the presence of bronchopleural fistula. Pleural effusion was detected unilaterally in all cases ( 8 cases on the right). The amount of pleural effusion at the onset of NTM pleuritis was small in 14 patients (93\%) and moderate in 1 patient $(7 \%)$.

\section{Clinical Course of NTM Pleuritis}

In 7 of 15 cases (47\%), NTM pleuritis developed within 2 years after the diagnosis of pulmonary NTM, whereas in 4 patients $(27 \%)$ pulmonary NTM was diagnosed simultaneously with pleuritis (Table 4). Preexisting pulmonary NTM had not been treated with chemotherapy in 6 of 11 cases. After the diagnosis of NTM pleuritis, 11 patients were treated with 2-4 antimycobacterial medications (Table 4). Two cases with coexisting bacterial em-
Table 2. Clinical findings of pleural effusion

\begin{tabular}{ll}
\hline Pathogens $(n=15)$ & \\
Mycobacterium avium & $9(60)$ \\
Mycobacterium kansasii & $2(13)$ \\
Mycobacterium intracellulare & $1(7)$ \\
Mycobacterium abscessus complex & $1(7)$ \\
Mycobacterium fortuitum & $1(7)$ \\
Mycobacterium scrofulaceum & $1(7)$ \\
\hline Differential cell counts $(n=12)$ & \\
Neutrophil predominant & $9 / 12(75)^{\mathrm{a}}$ \\
Lymphocyte predominant & $3 / 12(25)$ \\
\hline ADA, U/L $(n=10)$ & \\
Mean \pm SD & $152.7 \pm 86.7$ \\
Range & $43.4-303$ \\
\hline
\end{tabular}

Figures in parentheses are percentages. ADA, adenosine deaminase; SD, standard deviation. ${ }^{\text {a }}$ Bacterial empyema coexisted in 2 cases.
Table 3. Radiological findings of NTM pleuritis $(n=15)$

\begin{tabular}{lr}
\hline Lung lesion over $50 \%$ of the total lung field & $11(73)$ \\
Nodular bronchiectasis dominant & $5(33)$ \\
Fibrocavitary features dominant & $10(67)$ \\
Subpleural cavities present & $11(73)$ \\
Air-fluid level present in the pleural space & $14(93)$ \\
Pleural thickening & $11(73)$ \\
\hline Amount of pleural effusion ${ }^{\mathrm{a}}$ & \\
$\quad$ Small & $14(93)$ \\
$\quad$ Moderate & $1(7)$ \\
$\quad$ Large & $0(0)$ \\
\hline
\end{tabular}

Figures in parentheses are percentages. NTM, nontuberculous mycobacterium. ${ }^{\text {a }}$ Small $=$ less than one-third of 1 hemithorax with chest radiography; moderate $=$ between one-third and two-thirds of 1 hemithorax; large $=$ more than two-thirds of 1 hemithorax.

pyema were treated only with antimicrobial agents not effective against NTM. Chest tube drainage was performed in 11 cases, and in 6 of the 11 cases surgical approaches were added (Table 4). While pleural biopsies were performed in all 6 cases, acid-fast bacillus smears were positive in 3 patients and cultures of pleural tissue were positive in 2 patients (Fig. 1). Three patients, including 2 cases with coexisting bacterial empyema, were lost to follow-up. The amount of pleural effusion of 2 alive 
Table 4. Clinical course of the 15 patients

\begin{tabular}{|c|c|c|c|c|c|c|c|c|}
\hline $\begin{array}{l}\text { Age (years), } \\
\text { sex }\end{array}$ & $\begin{array}{l}\text { Period from } \\
\text { pulmonary NTM } \\
\text { to pleuritis }\end{array}$ & Pathogens & $\begin{array}{l}\text { Chemotherapy } \\
\text { before pleuritis }\end{array}$ & $\begin{array}{l}\text { Pneumo- } \\
\text { thorax }\end{array}$ & $\begin{array}{l}\text { Chemotherapy } \\
\text { after pleuritis }\end{array}$ & Drainage & $\begin{array}{l}\text { Additional } \\
\text { surgical } \\
\text { procedure }^{\mathrm{a}}\end{array}$ & Clinical course \\
\hline 69 , male & 1 year & M. forutuitum & $(-)$ & $(-)$ & CAM, LVFX, AMK & $(+)$ & $(+)$ & alive (9 years) \\
\hline 70 , male & simultaneous & M. abscessus & $(-)$ & $(-)$ & CAM, IMP/CS, AMK & $(+)$ & $(+)$ & alive (7 years) \\
\hline 64 , male & 10 months & M. avium & $(-)$ & $(+)$ & CAM, RFP, EB, KM & $(+)$ & $(+)$ & alive (5 years) \\
\hline 57, male & simultaneous & M. kansasii & $(-)$ & $(+)$ & INH, RFP, EB & $(+)$ & $(-)$ & lost to follow-up \\
\hline 78 , male & 5 years & M. intracellulare & $\begin{array}{l}\text { CAM, RFP, EB } \\
\text { (4 years) }\end{array}$ & $(-)$ & CAM, RFP, EB, KM & $(-)$ & $(-)$ & $\begin{array}{l}\text { dead ( } 3 \text { months) } \\
\text { by NTM pleuritis }\end{array}$ \\
\hline 78 , male & 3 months & M. avium & $\begin{array}{l}\text { CAM, RFP, EB } \\
\text { (3 months) }\end{array}$ & $(-)$ & CAM, RFP, EB, KM & $(-)$ & $(-)$ & alive (3.5 years) \\
\hline 73 , female & 1 year & M. kansasii & $(-)$ & $(-)$ & INH, RFP, EB & $(-)$ & $(-)$ & alive ( 4.5 years) \\
\hline 81 , female & 5 years & M. avium & $\begin{array}{l}\text { CAM, RFP, EB } \\
\text { (3 years) }\end{array}$ & $(+)$ & CAM, RFP, EB, KM & $(+)$ & $(-)$ & alive (5 years) \\
\hline 75 , female & 10 years & M. scrofulaceum & $(-)$ & $(+)$ & CAM, RFP, EB, KM & $(+)$ & $(-)$ & $\begin{array}{l}\text { dead ( } 1 \text { month) } \\
\text { by NTM pleuritis }\end{array}$ \\
\hline 85 , female & 40 years & M. avium & $(-)$ & $(-)$ & antibiotics & $(-)$ & $(-)$ & lost to follow-up \\
\hline 56 , male & 8 years & M. avium & $\begin{array}{l}\text { CAM, RFP, EB } \\
\text { (7 years) }\end{array}$ & $(-)$ & CAM, RFP, EB, KM & $(+)$ & $(+)$ & $\begin{array}{l}\text { dead ( } 5 \text { years) } \\
\text { by pneumonia }\end{array}$ \\
\hline
\end{tabular}

NTM, nontuberculous mycobacterium; CAM, clarithromycin; RFP, rifampicin; EB, ethambutol; KM, kanamycin; LVFX, levofloxacin; AMK, amikacin; GRNX, garenoxacin; IMP/CS, imipenem/cilastatin; INH, isoniazid. ${ }^{a}$ Fenestration operation, pyothorax curettage, and thoracoplasty.

patients treated only with antimycobacterial medications in consideration of age, performance status, and general condition gradually deteriorated. Two patients died from NTM pleuritis, and 1 patient died from pneumonitis during a mean of 1.8 years of follow-up. The median survival period of the 3 dead patients from the diagnosis of NTM pleuritis was 3 months.

\section{Discussion}

NTM pleuritis is an uncommon condition that has been reported in immunocompromised hosts $[14,15]$. As the prevalence of NTM infection has been increasingly reported worldwide, the number of case reports on NTM pleuritis has increased. Kobashi et al. [26] revealed that pneumothorax occurred in $4.1 \%$ of NTM patients and
NTM pleuritis arose secondarily in one-third of the pneumothorax cases. Ichiki et al. [23] reported that the frequency of pleural effusion in patients with pulmonary NTM was $3.4 \%$. In our report, $1.4 \%$ of cases with pulmonary NTM developed pleuritis with NTM isolated from pleural effusion. The most common pathogen of the pleuritis was M. avium, followed by M. kansasii and M. intracellulare, similar to previous reports [25]. There were 2 cases of NTM pleuritis coexisting with another bacterial infection. Although these cases fulfilled our criteria of NTM pleuritis, NTM in the pleural effusion may not have pathogenic significance because these patients improved with only antibacterial therapy. Most of our cases revealed a high leukocyte count with a low percentage of lymphocytes and elevated ADA levels in the pleural effusion, which was similar to previous reports $[23,25]$. 

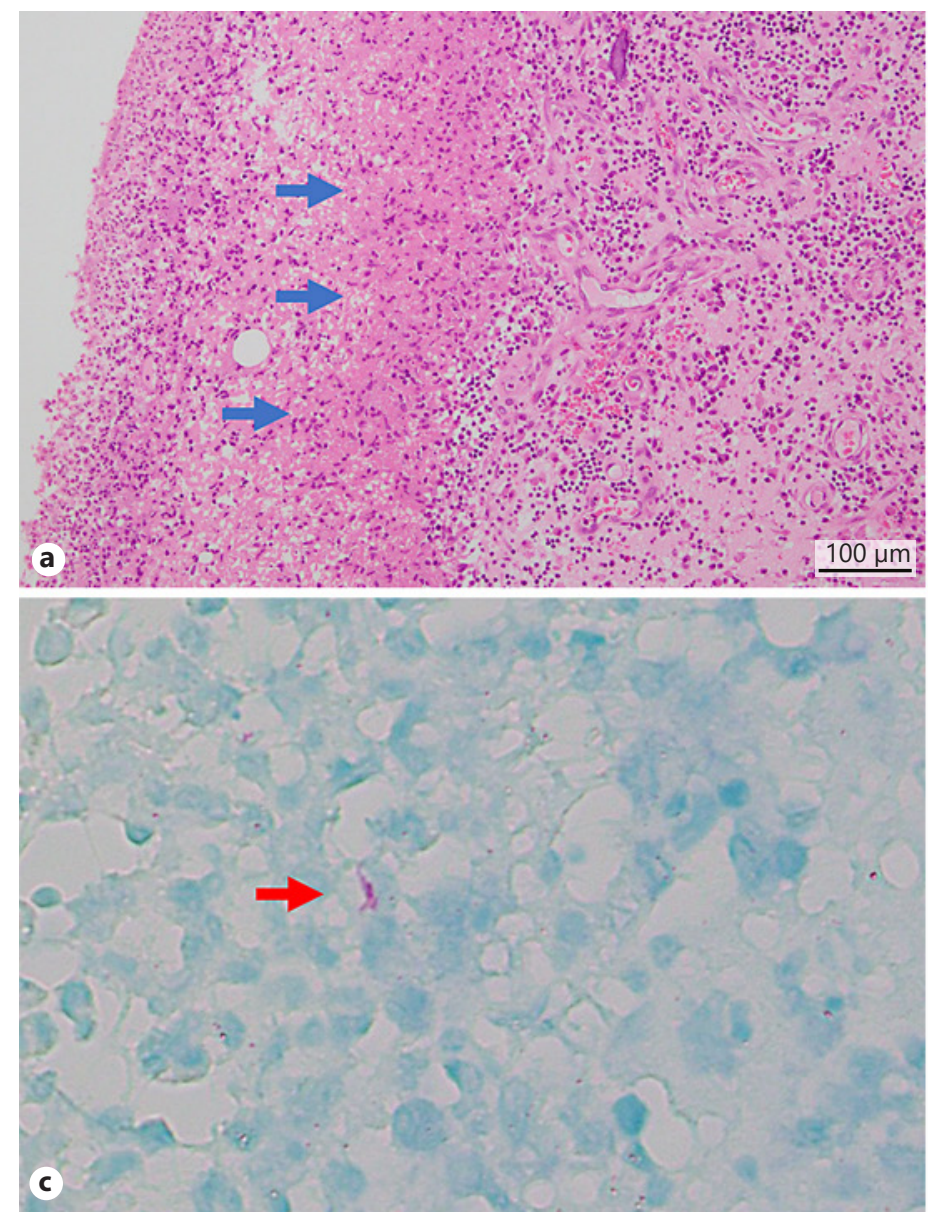

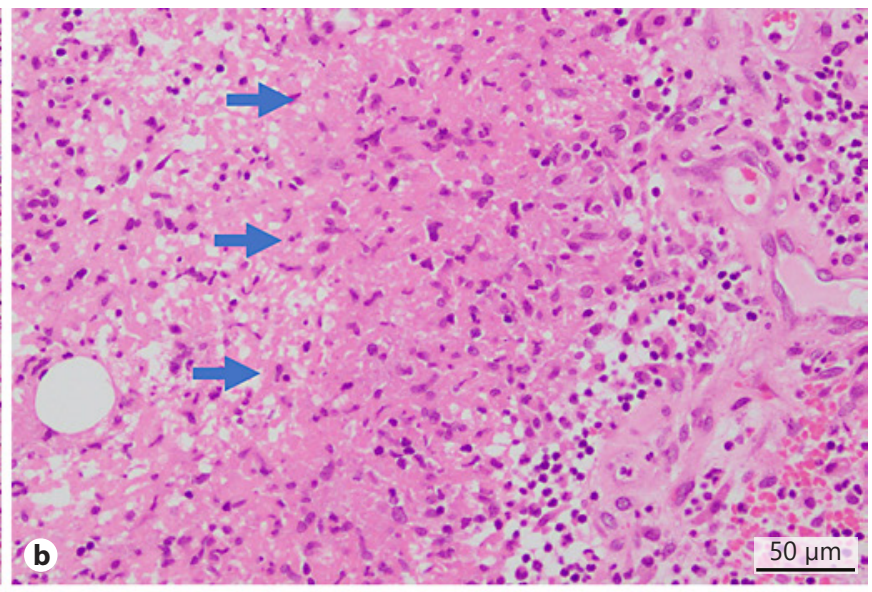

Fig. 1. Pathological findings of NTM pleuritis. HE stain of the pleura obtained by surgical therapy $(\mathbf{a}, \mathbf{b})$ or Ziehl-Neelsen staining (c) are shown. a, b Subpleural epithelial cell granulomas are shown by blue arrows. c Ziehl-Neelsen-positive bacillus is shown by a red arrow. NTM, nontuberculous mycobacterium.
Although unclear, the pathogenesis of NTM pleuritis has been considered to be similar to that of tuberculous pleuritis, reported to develop due to leakage or rupture of a subpleural focus, extension of infection from the thoracic lymph nodes, or hematogenous spread [30]. NTM pleuritis may occur via lymphogenous or hematogenous spread in an immunocompromised situation, such as in case of the acquired immunodeficiency syndrome [14, 15] or advanced cancers. However, since NTM is usually less virulent than $M$. tuberculosis, in most cases, the mechanism of NTM pleuritis was primarily suspected to be the perforation of pulmonary NTM disease or spread of inflammation to the pleura $[16,18,19,22,31,32]$. Our study revealed that $73 \%$ of cases had subpleural cavitation, and most cases were considered to present bronchopleural fistula or pneumothorax according to the radiological findings. This result supports that NTM pleuritis developed with leakage or perforation of pulmonary NTM disease.

Clinical Features of NTM Pleuritis
The onset of NTM pleuritis after pulmonary NTM has not been previously reported. Kobashi et al. [26] reported that 7 of 9 cases (67\%) were diagnosed with pneumothorax within 1 year after pulmonary NTM. This study revealed that $47 \%$ of NTM pleuritis cases occurred within 1 year after the diagnosis of pulmonary NTM, and $27 \%$ of patients were diagnosed simultaneously. Although lung lesions preexisted in 11 cases of pleuritis, 6 of them had not been treated with chemotherapy. Treating pulmonary NTM at an early stage can prevent the progression of NTM, such as formation of cavitation, parenchymal destruction, or extension of inflammation to the pleura and development of NTM pleuritis.

The mortality of the pleuritis patients with NTM isolated from pleural effusion was reported as $37-66 \%$ at 1 year $[25,26]$. A recent report by Park et al. [31] demonstrated that the mortality from NTM pleuritis was $14.3 \%$ during a median of 37.4 months of follow-up. They also emphasized the importance of immediate therapy using 
a multidisciplinary approach against NTM pleuritis. In this study, the mortality rate of follow-up patients was $17 \%$ ( 2 of 12 cases) at 1 year and 25\% (3 of 12 cases) during a mean of 1.8 years of follow-up, which was comparable or better than in the previous studies $[25,26,31]$. Because our cases were younger and had a better performance status than those in the previous studies, drainage and surgical approach could be performed more vigorously, which might have led to a better prognosis of NTM pleuritis.

The current study has several limitations. First, this study was a retrospective analysis of patients from a single institution. The therapeutic regimen or decisions varied depending on the patients' conditions and the clinical experience of the attending physicians. Second, in this retrospective study, the cause of death was based on clinical records of the attending physicians. Although we defined that 2 patients died from NTM pleuritis and 1 patient from other than NTM infection, the precise causes of death could not be verified in the absence of an autopsy. Third, since NTM pleuritis is a rare condition, the number of patients examined in our study is small. This is a case series study and did not include a control group for statistical analysis. Further studies with a much larger number of cases are required to confirm our results.
In conclusion, NTM pleuritis was difficult to treat by medication alone, and the prognosis was poor. In addition to antimycobacterial medications, surgical procedures in the early stages should be considered to treat NTM pleuritis.

\section{Disclosure Statement}

The authors declare no conflicts of interest associated with this study.

\section{Funding Sources}

The authors have not received any funding for this study.

\section{Author Contributions}

T.A. had full access to the data, takes responsibility for their integrity, and had the final responsibility for the decision to submit the paper for publication. All authors are responsible for the study concept and design. T.A., M.K., H.M., K.T., R.S., N.O., H.N., and K.O. are responsible for acquisition of data. All authors are responsible for analysis or interpretation of data, drafting of the manuscript, and manuscript revision.

\section{References}

1 Glassroth J: Pulmonary disease due to nontuberculous mycobacteria. Chest 2008; 133 : 243-251.

2 Wassilew N, Hoffmann H, Andrejak C, Lange C: Pulmonary disease caused by non-tuberculous mycobacteria. Respiration 2016;91:386402.

3 Good RC, Snider DE: Isolation of nontuberculous mycobacteria in the United States. J Infect Dis 1982;146:829-833.

4 O'Brien RJ, Geiter LJ, Snider DE: The epidemiology of nontuberculous mycobacterial diseases in the United States: results from a national survey. Am Rev Respir Dis 1987;135: 1007-1014.

5 Horsburgh CJ Jr, Selik RM: The epidemiology of disseminated nontuberculous mycobacterial infection in the acquired immunodeficiency syndrome (AIDS). Am Rev Respir Dis 1989;139:4-7.

6 Griffith DE, Aksamit T, Brown-Elliott BA, Catanzaro A, Daley C, Gordin F, Holland SM, Horsburgh R, Huitt G, Iademarco MF, Iseman M, Olivier K, Ruoss S, von Reyn CF, Wallace RJ Jr, Winthrop K: An official ATS/IDSA statement: diagnosis, treatment, and prevention of nontuberculous mycobacterial diseases. Am J Respir Crit Care Med 2007;175:367-416.
7 Wallace RJ Jr, Glassroth J, Griffith DE, Olivier $\mathrm{KN}$, Cook JL, Gordin F: Diagnosis and treatment of disease caused by nontuberculous mycobacteria. This official statement of the American Thoracic Society was approved by the Board of Directors, March 1997. Am J Respir Crit Care Med 1997;156:S1-S25.

8 Cassidy PM, Hedberg K, Saulson A, McNelly E, Winthrop KL: Nontuberculous mycobacterial disease prevalence and risk factors: a changing epidemiology. Clin Infect Dis 2009; 49:e124-e129.

9 Simons S, van Ingen J, Hsueh PR, Van Hung N, Dekhuijzen PN, Boeree MJ, van Soolingen D: Nontuberculous mycobacteria in respiratory tract infections, eastern Asia. Emerg Infect Dis 2011;17:343-349.

10 van Ingen J, Bendien SA, de Lange WC, Hoefsloot W, Dekhuijzen PN, Boeree MJ, van Soolingen D: Clinical relevance of non-tuberculous mycobacteria isolated in the Nijmegen-Arnhem region, the Netherlands. Thorax 2009;64:502-506.
11 Sakakibara Y, Suzuki Y, Fujie T, Akashi T, Iida T, Miyazaki Y, Eishi Y, Inase N: Radiopathological features and identification of mycobacterial infections in granulomatous nodules resected from the lung. Respiration 2017;93:264-270.

12 Namkoong $\mathrm{H}$, Kurashima A, Morimoto K, Hoshino Y, Hasegawa N, Ato M, Mitarai S: Epidemiology of pulmonary nontuberculous mycobacterial disease, Japan. Emerg Infect Dis 2016;22:1116-1117.

13 Sakatani M: The non-tuberculous mycobacteriosis (in Japanese). Kekkaku 2005;80:2530.

14 Haider A, Schliep T, Zeana C: Nontuberculous mycobacterium disease with pleural empyema in a patient with advanced AIDS. Am J Med Sci 2009;338:418-420.

15 Agheli A, Tehranirad M, Cofsky R: An unusual presentation of Mycobacterium fortuitum: massive isolated empyema in a patient with HIV. Med Gen Med 2006;8:90.

16 Park SU, Koh WJ, Kwon OJ, Park HY, Jun HJ, Joo EJ, Lee NY, Kim TS, Lee KS, Park YK: Acute pneumonia and empyema caused by Mycobacterium intracellulare. Intern Med 2006;45:1007-1010. 
17 Kotani K, Hirose Y, Endo S, Yamamoto H, Makihara S: Surgical treatment of atypical Mycobacterium intracellulare infection with chronic empyema: a case report. J Thorac Cardiovasc Surg 2005;130:907-908.

18 Matsumoto T, Otsuka K, Tomii K: Mycobacterium fortuitum thoracic empyema: a case report and review of the literature. J Infect Chemother 2015;21:747-750.

19 Asai K, Urabe N: Acute empyema with intractable pneumothorax associated with ruptured lung abscess caused by Mycobacterium avium. Gen Thorac Cardiovasc Surg 2011;59: 443-446.

20 Lim JG, O SW, Lee KD, Suk DK, Jung TY, Shim TS, Chon GR: Mycobacterium intracellulare pleurisy identified on liquid cultures of the pleural fluid and pleural biopsy. Tuberc Respir Dis (Seoul) 2013;74:124-128.

21 Lim JG, O SW, Lee KD, Suk DK, Jung TY, Shim TS, Chon GR: Mycobacterium aviumintracellulare pleuritis with massive pleural effusion. Eur Respir J 1995;8:1428-1429.

22 Jo KW, Kim JW, Hong Y, Shim TS: A case of empyema necessitatis caused by Mycobacterium abscessus. Respir Med Case Rep 2012;6: $1-4$.
23 Ichiki H, Ueda S, Watanabe A, Sato C, Abe M: Nontuberculous pulmonary mycobacteriosis complicated by pleuritis (in Japanese). Nihon Kokyuki Gakkai Zasshi 2011;49:885-889.

24 Christensen EE, Dietz GW, Ahn CH, Chapman JS, Murry RC, Anderson J, Hurst GA: Initial roentgenographic manifestations of pulmonary Mycobacterium tuberculosis, $M$ kansasii, and $M$ intracellularis infections. Chest 1981;80:132-136.

25 Shu CC, Lee LN, Wang JT, Chien YJ, Wang JY, Yu CJ: Non-tuberculous mycobacterial pleurisy: an 8-year single-centre experience in Taiwan. Int J Tuberc Lung Dis 2010;14:635641.

26 Kobashi Y, Mouri K, Obase Y, Kato S, Oka M: Clinical analysis of patients with pulmonary nontuberculous mycobacterial disease complicated by pneumothorax. Intern Med 2013; 52:2511-2515.

27 Takakura S, Tsuchiya S, Isawa Y, Yasukawa K, Hayashi T, Tomita M, Suzuki K, Hasegawa T, Tagami T, Kurashima A, Ichiyama S: Rapid detection of Mycobacterium tuberculosis in respiratory samples by transcription-reverse transcription concerted reaction with an automated system. J Clin Microbiol 2005;43: 5435-5439.
28 Casarini M, Ameglio F, Alemanno L, Zangrilli P, Mattia P, Paone G, Bisetti A, Giosuè S: Cytokine levels correlate with a radiologic score in active pulmonary tuberculosis. Am J Respir Crit Care Med 1999;159:143-148.

29 Zubrod CG, Schneiderman M, Frei E, Brindley C, Gold GL, Shnider B, Oviedo R, Gorman J, Jones R, Jonsson U, Colsky J, Chalmers T, Ferguson B, Dederick M, Holland J, Selawry O, Regelson W, Lasagna L, Owens AH: Appraisal of methods for the study of chemotherapy in man: comparative therapeutic trial of nitrogen mustard and thiophosphoramide. J Chronic Dis 1960;11:7-33.

30 Sahn SA, Iseman MD: Tuberculous empyema. Semin Respir Infect 1999;14:82-87.

31 Park S, Jo KW, Lee SD, Kim WS, Shim TS: Clinical characteristics and treatment outcomes of pleural effusions in patients with nontuberculous mycobacterial disease. Respir Med 2017;133:36-41.

32 Ikeda M, Takahashi K, Komatsu T, Tanaka T, Kato T, Fujinaga T: The frequency and treatment of pneumothorax associated with pulmonary nontuberculous mycobacterial infection. Gen Thorac Cardiovasc Surg 2017;65: 117-121. 